Article No. 261

DOI: https://doi.org/10.26881/srg.2021.8.17

(Научно-исследовательская статья / Research article

ZNACZEK LICENCJI

Copyright (C) 2021 SRG and M. Shaternik ${ }^{1}$

Citation:

Шатерник, М. (2021). Методологические и предметные особенности русскоязычной программы философского исследования дискурса. Studia Rossica Gedanensia, 8: 287-294.

DOI: https://doi.org/10.26881/srg.2021.8.17

Shaternik, M. (2021). Metodologičeskie i predmetnye osobennosti russkoâzyčnoj programmy filosofskogo issledovaniâ diskursa. Studia Rossica Gedanensia, 8: 287-294. DOI: https://doi.org/10.26881/srg.2021.8.17

\title{
МЕТОДОЛОГИЧЕСКИЕ И ПРЕДМЕТНЫЕ ОСОБЕННОСТИ РУССКОЯЗЫЧНОЙ ПРОГРАММЫ ФИЛОСОФСКОГО ИССЛЕДОВАНИЯ ДИСКУРСА
}

\section{МИХАИЛ ШАТЕРНИК / MIKHAIL SHATERNIK ${ }^{2}$}

Национальная академия наук Беларуси / National Academy of Sciences of Belarus

Институт философии / Institute of Philosophy

Отдел философии литературы и эстетики / Philosophy of Literature and Aesthetics Department ул. Сурганова 1, корп. 2, BY-220072, Минск, Беларусь / Surganova St. 1/2, BY-220072, Minsk,

\section{Belarus}

Corresponding Author e-mail: 33mg@mail.ru

ORCID: https://orcid.org/0000-0003-4610-6815

(получено / received 2.07.2021; принято / accepted 16.07.2021)

\footnotetext{
This is an open-access article distributed under the terms of the Creative Commons AttributionShareAlike 4.0 International (CC BY-SA 4.0 https://creativecommons.org/licenses/by-sa/4.0/) which permits use, distribution, and reproduction in any medium, provided that the article is properly cited, the use is non-commercial, and no modifications or adaptations are made. Publisher: University of Gdańsk. Faculty of Language [Wydawca: Uniwersytet Gdański. Wydział Filologiczny]

2 Also transliterated: Mihail Šaternik (Polish) [KW].
} 


\section{Abstract \\ Methodological and subject features of the Russian-language program for the philosophical research of discourse}

The article provides an overview of the philosophical ideas of discourse that have been developed in Russian-language studies in recent years. By identifying the methodological features of the Russian-language discourse research program, as well as analyzing the application of the discourse approach to cultural studies, it becomes possible to understand the specifics of this approach and to outline its prospects as a method of social and humanist research.

Keywords: discourse, Russian-language program, methodological features, subject features, speech-thinking activity, cultural intention, sense formation, concept.

\section{Резюме}

В статье осуществлен обзор философских представлений о дискурсе, которые сложились в его русскоязычных исследованиях последних лет. Посредством выделения методологических и предметных особенностей русскоязычной программы исследования дискурса, а также анализа применения дискурсного подхода в культурологических исследованиях, становится возможным понять специфику данного подхода и наметить его перспективность как метода социально-гуманитарных исследований.

Ключевые слова: дискурс, русскоязычная программа, методологические особенности, предметные особенности, речемыслительная деятельность, культурологическая интенция, смыслообразование, концепт.

Актуальность изучения дискурса обусловлена тем, что его структура в контексте когнитивного и коммуникативного функционирования оказывает существенное влияние на процессы мышления и взаимопонимания людей. Понятие «дискурс» в настоящее время не имеет общепризнанной дефиниции. Данное понятие варьируется в зависимости от методологических и предметных особенностей программы, в рамках которой оно рассматривается.

При том, что работы по тематике дискурса достаточно различны, можно попытаться определить характерные для них методы исследования дискурса и его предметную интерпретацию. По определению основательницы российской научной школы «логического анализа языка» Н.Д. Арутюновой, дискурс представляет собой «связный текст в совокупности с внелингвистическими, прагматическими, социокультурными, психологическими и другими факторами... речь, погруженную в жизнь» (Арутюнова 1990: 136-137).

С одной стороны, такая методологически междисциплинарная трактовка позволила ей наметить пути решения проблемы связности текста и выявить 
структурное многообразие дискурса как предмета исследования, с другой прояснить методологические стратегии исследования дискурса (Арутюнова 1998) посредством использования методов и категорий логики, а также методов концептуального анализа языка в их отношении к мышлению и знанию.

Также нередко в русскоязычном академическом пространстве применяется дискурсный подход для решения задач в таких сферах, как коммуникативная лингвистика, когнитивная лингвистика, лингвокультурология и философские исследования.

В теории дискурса М.Л. Макарова (Макаров 2003) был намечен путь корреляции лингвистических и философских методологических построений, а также представлен оригинальный опыт синтеза прагмалингвистики, социального конструкционизма, когнитивной психологии, интерпретативного интеракционизма и других исследовательских подходов в аналитической модели, рассматривающей языковое общение как воспроизводство феноменологически переживаемой интерсубъективности.

Л.Д. Петряков, исследуя дискурс в его онтологическом и гносеологическом аспектах, отмечает, что дискурс является «ментальной волной, в которой выражается внимание человека к какому-либо феномену его жизни, а в содержании - онтологическое, когнитивное, этическое, аксиологическое, практическое отношение к этому феномену» (Петряков 2014: 4).

Осуществляя лингвистическую типологию текстов относительно коммуникативной ситуации и рассматривая дискурс сквозь призму «текст - контекст смысл», И.Т. Касавин отмечал наличие в дискурсе аксиологических функций, полагая, что универсальность контекста роднит его с наукой, указывал на его близость дискурсу искусства благодаря субъективности языковой артикуляции. И.Т. Касавин определял дискурс как

(...) неоконченный живой текст, взятый в момент его непосредственной включенности в акт коммуникации, в ходе его взаимодействия с контекстом. От дискурса отличается текст, который уже отчужден от автора пространственными, временными и иными индексикальными параметрами (Касавин 2008: 295).

Дискурс трактовался исследователем в контексте его вовлеченности в социальную ситуацию, в ситуацию проговаривания и переживания этого проговаривания, обращенности к Другому. Здесь проявляется первая особенность русскоязычной традиции - дискурс рассматривается в противопоставлении тексту. По замечанию И.Т. Касавина, «из всех социально-политических оттенков смысла термина дискурс теоретически значимым представляется только тот, который подразумевает живой социальный акт дискуссии, или коммуникации» (Касавин 2008: 295).

Еще одной характерной чертой русскоязычных исследований дискурса является культурологическая интенция к определению дискурсивных механизмов образования культурных феноменов. В частности, Е.В. Кожемякин, разработавший полипараметральную модель анализа дискурса (Кожемякин 2008), полагает, что 
(...) дискурсная методология может быть рассмотрена в качестве подхода, предполагающего многоаспектную интерпретацию культуры, в которой гармонично интегрируются все указанные бинарные оппозиции, раскрывается взаимодействие между дискурсной формой и содержанием культуры, а также фиксируется событийность как её атрибутивное свойство. Этот подход позволяет: интерпретировать как универсальные, так и уникальные характеристики культуры; проанализировать знаковый характер культуры в единстве ее означающих и означаемых; рассмотреть субъекта как рефлексирующего агента культуры и как цель любого культурного проекта; определить культуру и как диалогичный процесс взаимодействия, и как множество голосов, в котором происходит одновременное самоутверждение участников коммуникации; анализировать культуру в аспекте ее структурно-функционального и повседневно-жизненного устройства; рассмотреть культурные феномены как единство текста и контекста; изучить культурные практики во взаимосвязи коммуникативно-языковых, деятельностных и ментально-когнитивных феноменов (Кожемякин 2020).

\section{Е.В. Переверзев отмечает, что при определении}

(...) сущности современного культурологического подхода в дискурсной теории труднейшей задачей является эксплицирование связи между человеком, его эволюционными биологическими, социальными чертами, культурой и дискурсом. Другой важной проблемой является установление максимально четких границ направления, которое, несомненно, заимствует свои фундаментальные основания у таких наук, как философия, культурология, социолингвистика, антропология, критические теории и многих других (Переверзев 2020).

К.А. Зуев изучил дискурс с точки зрения его речемыслительной деятельности, которая, по мнению исследователя, «регламентируется социокультурными кодами (правилами, традициями и ценностями)» (Зуев 2010: 6). А.П. Огурцов выделил эйдетический и аксиологический дискурсы, где последнему, помимо ориентированности на категорию блага, присуща укорененность в ценностях и оценках (Огурцов 1998: 7). Огурцов изучал историческую динамику дискурса и выявил произошедший в дискурсе разрыв гносеологии и этики, обусловленный различиями в их предметности и телеологии.

Белорусская исследовательница С.В. Воробьева отмечает, что благодаря включению в дискурс категории «Другой», а также благодаря переосмыслению категорий «ответственность», «согласие», «справедливость» был осуществлен переход к пониманию дискурса как области формирования этоса (Воробьева 2002). В работе Онтология дискурса Е.В. Сидоров описал целостную онтологию речевой коммуникации на основе свойственной ей необходимости. Дискурс понимается им через призму речевой коммуникации как «интеракция, опосредуемая механизмом знаковой координации коммуникативных деятельностей общающихся» (Сидоров 2008: 10). Автор рассматривает дискурс как необходимое звено речевой коммуникации, представляющее собой сопряженную знаковую модель коммуникативных деятельностей говорящего и реципиента.

В коллективной монографии Современный моральный дискурс (Колмаков 2015) отмечается, что «начала морального дискурса кроются в моральном подсознании», а сам моральный дискурс понимается как «способ обозначения и осмысления современных моральных проблем как личных проблем, личного 
смысла, личной экзистенции, ощущаемой как моральный смысл всего человечества» (Колмаков 2015: 6). Моральный дискурс понимается как совокупность речей о морали, которая формирует смысл личной экзистенции, и как моральный смысл для всего человечества.

В дискурсе осуществляется взаимодействие мышления и языка, ибо, «как показывает опыт лингвистики и когнитивной науки, мыслительные категории практически неотделимы от языковых категорий», - полагает А.Н. Баранов (Баранов 2001: 294). В этом плане дискурс может быть понят как система общепринятых или социальных смыслов, которую в качестве своего контекста предполагает мышление, то есть мышление и дискурс связаны общими процессами, дающими совместный когнитивный эффект. Таким образом, одна из важнейших функций морального дискурса раскрывается в связи с его ролью в мыслительных процессах.

В русскоязычном пространстве изучения дискурса встречаются работы, в которых определен механизм образования смысла в дискурсе. В работе Дискурс как смыслопорождающая категория Н.В. Алефиренко отмечает, что

(...) сложные смысловые конфигурации, нуждающиеся в разнообразных средствах вторичного знакообозначения, зарождаются в глубинных пластах дискурса. Именно здесь при наличии необходимых условий обостряются противоречия между структурообразующими дискурс факторами, в результате чего высекаются первые искры лингвокреативного стимулирования процессов вторичного семиозиса (Алефиренко 2005: 5).

Это значит, что в когнитивной структуре дискурса происходит образование смысла на основе синтетического взаимодействия его различных пластов. Вторичный семиозис следует понимать как процесс выстраивания осмысленной реальности в дискурсе.

Также, по мысли Н. Алефиренко, базовым элементом когнитивной структуры является концепт:

Если развести мышление как процесс отражения действительности в сознании человека и мысль как продукт мыслительной деятельности, то можно принять имплицитно существующую точку зрения, согласно которой единицей мысли является культурный концепт, служащий ценностно-смысловой репрезентацией определенного коллективного опыта (Алефиренко 2014: 175).

Таким образом, роль концепта в когнитивной структуре дискурса становится ключевой. Поэтому рассмотрение концепта как неотъемлемого элемента структуры дискурса можно также отнести к специфике русскоязычных дискурсных исследований.

Как отмечает М.Ю. Олешков, для изучения специфики когнитивного пространства дискурса особое внимание следует уделить «интенционально заданной номенклатуре концептов и репрезентирующих их языковых структур» (Олешков 2009: 81). Дискурсивно-когнитивный анализ речевого взаимодействия возможен с учетом контекста, в котором выделяется смысловое ядро (базовый концепт), отражающее на «онтологическом уровне структуру общения и деятельности, и периферия - совокупность интенционально обусловленных локальных концептов, пропозиционально цементирующих дискурс» (Олешков 2010: 330). 
Как пишет специалист по концептам русского языка Ю.С. Степанов, концепт - это «как бы сгусток культуры в сознании человека; то, в виде чего культура входит в ментальный мир человека... то, посредством чего человек сам входит в культуру» (Степанов 2004: 42). Изменяя душу индивида, обдумывающего вещь, концепт «включается, помимо духовной культуры в собственном смысле этого слова, еще и в структуры общения и в мыслительные категоризации» (Степанов 2004: 47). Концепт формируется в результате погружения в среду культурноценностных категорий и «проговаривается» в их контексте. Его дискурсивность выражена в том, что «при своем формировании концепт предполагает другого субъекта (слушателя, читателя), актуализируя смыслы в ответах на его вопросы» (Неретина 2001: 306-307).

Базовый концепт репрезентируется в глобальной теме дискурса, в когнитивной схеме, которая, в частности, «эксплицируется в коммуникативном фокусе диалога на пропозициональном уровне, в метакоммуникативных компонентах организации текста/дискурса, в дейктических элементах и др.» (Олешков 2009: 78). Базовый концепт проявляется также на уровне макроинтенции говорящих (в юридическом дискурсе - «закон», религиозном - «вера», политическом - «власть», в моральном - это «должное, нравственно правильное»). «Его непосредственная вербализация (актуализация на вербальном уровне) может отсутствовать в „теле” дискурса, а может, наоборот, явно проявляться в речи коммуникантов» (Макаров 2003: 5).

Под концептом понимается содержание словесного знака, которое принадлежит умственной, духовной или жизненно важной материальной сфере существования человека, выработано и закреплено общественным опытом народа, «имеющее в его жизни исторические корни, социально и субъективно осмысляемое» (Шведова 2005: 603).

Таким образом, в русскоязычных дискурсных исследованиях сложилось представление о дискурсе как о речемыслительной деятельности, регламентируемой социокультурными кодами (правилами, традициями и ценностями), определённой общественной практикой (наукой, правосудием, религией, политикой, образованием, медициной и т. п.), посредством которой люди - в границах данной практики - производят и транслируют свои знания и модели социального опыта, реализуют свои познавательные и/или коммуникативные потребности. Для данной методологической программы характерна культурологическая интенция, предполагающая применение дискурсного подхода для исследования феноменов культуры, а также для анализа процессов смыслообразования, мышления и коммуникации, с акцентированием роли концепта как неотъемлемого элемента структуры дискурса. В данной программе дискурс рассматривается в противопоставлении тексту.

\section{Библиография / References}

Alefirenko, N.F. (2005). Diskurs kak smysloporoždaûščâ kategoriâ (diskurs i vtoričnoe znakoobrazovanie). V: Jazyk. Tekst. Dyskurs. Vyp. 3. Stavropol': Stavropol'skij gosudarstvennyj pedynstitut: 5-13 [Алефиренко, Н.Ф. (2005). Дискурс как смыслопорождающая категория (дискурс 
и вторичное знакообразование). В: Язык. Текст. Дискурс. Вып. 3. Ставрополь: Ставропольский государственный пединститут: 5-13].

Alefirenko, N.F. (2014). Lingvokul'turologiâ. Cennostno-smyslovoe prostranstvo âzyka. Moskva: Flinta; Nauka [Алефиренко, Н.Ф. (2014). Лингвокультурология. Ценностно-смысловое пространство языка. Москва: Флинта; Наука].

Arutûnova, N.D.(1990). Diskurs. V: Lingvističeskij ènciklopedyčeskij slovar'. Moskva: Sovetskaâ ènciklopediâ: 136-137 [Арутюнова, Н.Д. (1990). Дискурс. В: Лингвистический энциклопедический словарь. Москва: Советская энциклопедия: 136-137].

Arutûnova, N.D. (1998). Âzyk i mir čeloveka. Vyp. 15. Moskva: Âzyki russkoj kul'tury [Арутюнова, Н.Д. (1998). Язык и мир человека. Вып. 15. Москва: Языки русской культуры].

Baranov, A.N. (2001). Vvedenie v prikladnû̂ lingvistiku. Moskva: Ẽditorial URSS [Баранов, А.Н. (2001). Введение в прикладную лингвистику. Москва: Эдиториал УРСС].

Kasavin, I.T. (2008). Tekst. Diskurs. Kontekst: vvedenie v social'nû̀ èpistemologî̂ âzyka. Moskva: Kanon+ [Касавин, И.Т. (2008). Текст. Дискурс. Контекст: введение в социальную эпистемотогию языка. Москва: Канон+].

Kožemâkin, E.A. (2008). Metodologičeskie problemy izučeniâ diskursnyh praktik. V: Trudy Instituta sistemnogo analiza Rossijskoj akademii nauk. T. 37. Moskva: 151-173 [Кожемякин, Е.А. (2008). Методологические проблемы изучения дискурсных практик. Труды Института системного анализа Российской академии наук. Т. 37. Москва: 151-173].

Kožemâkin,E.A.(2020).Diskursnyjpodhodkizučeniûkul'tury.(Online) http://www.discourseanalysis. org/ada1_1.pdf. (dostup: 23.02.2020) [Кожемякин, Е. Дискурсный подход к изучению культуpbl. (Online) http://www.discourseanalysis.org/ada1_1.pdf. (доступ: 23.02.2020)].

Kolmakov, V.Û. (2015). Sovremennyj moral'nyj diskurs. V: Sovremennyj moral'nyj diskurs. Krasnoârsk: Krasnoârskoe otdelenie Rossijskogo filosofskogo obŝestva. Sibirskij institut problem globalizacii: 5-13 [Колмаков, В.Ю. (2015). Современный моральный дискурс. В: Современньй моральный дискурс. Красноярск: Красноярское отделение Российского философского общества. Сибирский институт проблем глобализации: 5-13].

Makarov, M. (2003). Osnovy teorii diskursa. Moskva: Gnozis [Макаров, М. (2003). Основы теории дискурса. Москва: Гнозис].

Neretyna, S.S. (2001). Koncept. V: Novâ̂ filosofskaâ ènciklopediâ: v četyreh tomah. T. 2. Moskva: Nauka: 306-307 [Неретина, С.С. (2001). Концепт. В: Новая филособская энциклопедия: в четырех томах. Т. 2. Москва: Наука: 306-307].

Ogurcov, A.P. (1998). Blago i istina: linii rashoždeniâ $i$ shoždeniâ. V: Blago i istina: klassičeskie i neklassičeskie regulâtivy. Moskva: Nauka: 5-38 [Огурцов, А.П. (1998). Благо и истина: линии расхождения и схождения. В: Благо и истина: классические и неклассические регулятивы. Москва: Наука: 5-38].

Oleškov, M.Û. (2010). Kognitivnyj aspekt lingvističeskogo analiza teksta/diskursa. V: Aktual’nye problemy germanistiki, romanistiki i rusistiki: materialy meždunarodnoj naučnoj konferencii, Ekaterinburg, 5-6 fevralâ 2010 g. Č. 1. Ekaterynburg: Ural'skij gospeduniversitet: 325-331 [Олешков, М.Ю. (2010). Когнитивный аспект тингвистического анализа текста/дискурса. В: Актуальные проблемы германистики, романистики и русистики: материаль международной научной конференции, Екатеринбург, 5-6 февраля 2010 г. Ч. 1. Екатеринбург: Уральский госпедуниверситет: 325-331].

Oleškov, M.Û. (2009). Lingvokonceptual'nyj analiz diskursa (teoretičeskij aspekt). V: Diskurs, koncept, žanr. Nižnij Tagil: NTGSPA: 68-85 [Олешков, М. Ю. (2009). Лингвоконцептуальный анализ дискурса (теоретический аспект). В: Дискурс, конщепт, жанр. Нижний Тагил: НТГСПА: 68-85]. 
Pereverzev, E.V. (2020). Sovremennyj kul'turologičeskij analiz diskursa. (Online) http://www. discourseanalysis.org/ada1_1.pdf. http://www.discourseanalysis.org/ada1_1.pdf (dostup: 23.02.2020) [Переверзев, Е.В. Современный культурологический анализ дискурса. (Online) http://www.discourseanalysis.org/ada1_1.pdf. http://www.discourseanalysis.org/ada1_1.pdf. (доступ: 23.02.2020)].

Petrâkov, L.D. (2014). Diskursivnaâ real'nost' kak ob"ekt filosofskogo analiza: ontologičeskij i gnoseologičeskij aspekty: avtoreferat dissertacii... doktora filosofskih nauk: 09.00.01. Ivanovo: Ivanovskij gosuniversitet [Петряков, Л.Д. (2014). Дскурсивная реальность как объект философского анализа: онтологический и гносеологический аспекты: автореферат диссертаиии ... доктора философских наук: 09.00.01. Иваново: Ивановский госуниверситет].

Sidorov, E.V. (2008). Ontologiâ diskursa. Moskva: URSS: Izdatel'stvo LKY [Сидоров, Е. В. (2008). Онтология дискурса. Москва: URSS: Издательство ЛКИ].

Stepanov, Ju. (2004). Koncept V: Konstanty: slovar' russkoj kul'turŷ. Moskva: Âzyki slavânskih kul'tur: 42-83 [Степанов, Ю. (2004). Концепт В: Константы: словарь русской культуры. Москва: Языки славянских культур: 42-83].

Švedova, N.Û. (2005). Russkij âzyk: izbrannye raboty. Moskva: Âzyki slavânskih kul'tur [Шведова, Н.Ю. (2005). Русский язык: избранные работы. Москва: Языки славянской культуры].

Vorob’eva, S.V. (2002). Konfiguracii ètosa v koncepciâh ritoričeskoj kommunikacii Ė. Levinasa i H. Perel'mana. V: VII Meždunarodnye Kirillo-Mefodievskie čteniâ, posvâščennye Dnâm slavânskoj pis'mennosti i kultury: materialy čtenij, Minsk, 22-24 maâ 2001 g.: v dvuh častâh. Č. 1, kn. 2. Minsk: 243-251 [Воробьева, С.В. (2002). Конфигурации этоса в концепциях риторической коммуникации Э. Левинаса и Х. Перельмана. В: VII Международные Кирилло-Мефодиевские чтения, посвященные Дням славянской письменности и культуры: материалы чтений, Минск, 22-24 мая 2001 г.: в двух частях. Ч. 1, кн. 2. Минск: 243-251].

Zuev, K.A. (2010). Racional'nost': diskursnyj podhod. Moskva: Izdatel'stvo Rossijskoj akademii gosslužby pri Prezydente RF [Зуев, К.А. (2010). Рациональность: дискурсньй подход. Москва: Издательство Российской академии госслужбы при Президенте РФ].

Competing interests: The author declares that he has no competing interests. 